Esta obra está bajo una Licencia Creative Commons Atribución-NoComercial-Compartirlgual 4.0 Internacional

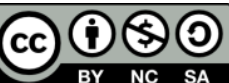

Análisis etnográfico del proceso de construcción de un accionar colectivo por el derecho a la vivienda y a la ciudad Agustina Girado

DOI: https://doi.org/10.24215/16696581e214

\title{
Análisis etnográfico del proceso de construcción de un accionar colectivo por el derecho a la vivienda y a la ciudad
}

\section{Ethnographic analysis of the process of building a collective action for the right to housing and the city}

\author{
Agustina Girado giradoagustina@gmail.com \\ http://orcid.org/0000-0003-3668-4275 \\ Grupo de Estudios Socioculturales del Conflicto; Facultad de Ciencias Sociales de Olavarría; \\ Universidad Nacional del Centro de la Provincia de Buenos Aires/Consejo Nacional de \\ Investigaciones Científicas y Técnicas (Argentina)
}

Resumen

El artículo da cuenta del proceso complejo y controvertido de conformación de un accionar colectivo en torno a la lucha por el derecho a la vivienda y a la ciudad en Tandil, provincia de

Question, Vol. 1, N. ${ }^{\circ}$ 64, octubre-diciembre 2019. ISSN 1669-6581

Instituto de Investigaciones en Comunicación | Facultad de Periodismo y Comunicación Social | Universidad Nacional de La Plata 
Agustina Girado Análisis etnográfico del proceso de construcción de un accionar colectivo por el derecho a la vivienda y a la ciudad

Buenos Aires. A través de un trabajo etnográfico realizado con agrupaciones sociales y políticas, se recuperan algunos aspectos presentes en la búsqueda que encarnaron en pos de construir un hacer y estar juntos. En ese proceso de creación de un accionar colectivo, sobre la base de la articulación de prácticas y conocimientos diversos vinculados con lo territorial, político y académico, también resulta posible advertir las particulares que adopta la problemática habitacional a nivel local y los modos disputados de pensar y construir ciudad. Sumado a ello, estas experiencias de acción tienen la potencialidad de invitarnos a seguir problematizando cómo se construye "lo colectivo" en ciudades medias, poniendo el énfasis en aquello que se produce haciendo, en el transcurrir mismo de los diversos actores sociales.

Palabras Clave: etnografía; accionar colectivo; problemática habitacional; ciudad media.

Abstract

The article gives an account of the complex and controversial process of forming a collective action around the struggle for the right to housing and the city in Tandil, province of Buenos Aires. Through an ethnographic work carried out with social and political groupings, some aspects present in the search that they incarnated in order to build a doing and being together are recovered. In this process of creating a collective action, based on the articulation of diverse practices and knowledge linked to the territorial, political and academic, it is also possible to notice the particulars adopted by the housing problem at the local level and the disputed ways of thinking and build city. Added to this, these experiences of action have the potential to invite us to continue problematizing how "the collective" is built in medium-sized cities, placing emphasis on what is produced by doing, in the course of the various social actors.

Keywords: ethnography; collective action; housing problems; middle city.

\section{Introducción}

Fue en el marco de una investigación doctoral en Antropología que me dispuse a abordar las particularidades que asume la problemática por el acceso al suelo urbano y la vivienda en la ciudad de Tandil (Buenos Aires). En este sentido, interesó recuperar el accionar de diferentes agrupaciones -sociales y políticas- abocados a la discusión de las formas de "hacer ciudad" (Girado, 2018) desplegadas por la gestión del Intendente Miguel Ángel Lunghi (2003 a la actualidad) (1) De este modo, tanto la implementación de ciertas políticas públicas urbanas 
Agustina Girado Análisis etnográfico del proceso de construcción de un accionar colectivo por el derecho a la vivienda y a la ciudad

destinadas a la estetización y espectacularización de la ciudad como parte de una estrategia de posicionamiento en el contexto nacional, instaurándose la marca ciudad (2) "Tandil, lugar soñado"; cuanto las intervenciones y soluciones que desde el gobierno local se brindaban a conflictos vinculados con el acceso al suelo urbano y la vivienda, ponían en el centro del debate un modelo de ciudad que profundizaba las desigualdades socio-espaciales y que privilegiaba el accionar de ciertos actores en desmedro de otros.

En lo que respecta a éste último aspecto, y durante la última década, los promotores inmobiliarios, empresarios de la construcción y del turismo, adquirieron un papel privilegiado en la producción del espacio urbano, habilitando un proceso especulativo que incrementó el precio del suelo urbano, de los alquileres y de las viviendas (Migueltorena, 2014). Ante esta situación, el gobierno de Lunghi no ha logrado garantizar el valor de uso de la ciudad para diversos actores sociales, encontrándose manifiestas dificultades en las posibilidades de acceso a la provisión pública de consumos colectivos (Silva y Gravano, 2013). En lo que respecta específicamente a la imposibilidad que tienen vastos sectores en poder concretar el derecho constitucional a una vivienda digna, en los últimos años se han producido ocupaciones de terrenos y conjuntos habitacionales inconclusos, incrementándose las conflictividades sociales en la ciudad. En este contexto, el eslogan municipal de "lugar soñado" posibilita establecer una frontera simbólico-imaginaria entre quienes se erigen en legítimos merecedores de soñar ese sueño de aquellos que viven su cara menos amable.

Atendiendo a lo mencionado, un actor colectivo que resultó central en la discusión de las formas de "hacer ciudad" por parte de la gestión de Lunghi, y que cobró centralidad en los inicios del trabajo de campo (octubre de 2013), fue la Asamblea por Tierra y Vivienda. La misma estaba integrada por docentes y estudiantes universitarios -pertenecientes a diferentes carreras- de la Universidad Nacional del Centro de la Provincia de Buenos Aires (UNICEN). La Asamblea tenía como objetivo principal poder constituirse en un actor relevante a nivel local abocado a la lucha por el acceso al suelo urbano y la vivienda, recuperando no sólo conocimientos científicos-académicos específicos sino también el trabajo territorial que desarrollaban en diferentes "barrios manchas" (3) (Gravano, 2005) de la ciudad en tanto (futuros) profesionales de la universidad comprometidos con problemáticas sociales.

En el presente artículo se busca poder reconstruir algunas prácticas, discursos e intervenciones motorizados por la Asamblea en tanto resulta un actor poco explorado en los trabajos sobre hábitat. Específicamente interesa abordar cómo ese tipo de organizaciones, impulsadas desde universidades y grupos de profesionales, adquieren centralidad no sólo en la gestión de ciertas demandas sociales y en la generación de vínculos con el Estado, sobre la base de la socialización de conocimientos y saberes que permiten complejizar el entendimiento 
Agustina Girado Análisis etnográfico del proceso de construcción de un accionar colectivo por el derecho a la vivienda y a la ciudad

y la gestión de la problemática habitacional local, sino también a partir de procurar construir un accionar colectivo junto a diversos actores sociales abocados a garantizar el derecho a la vivienda y el derecho a la ciudad (Thomasz, 2013).

Por todo lo expuesto, el presente artículo recupera parte del trabajo etnográfico desarrollado a mediados de 2014 y fines de 2015 en la ciudad de Tandil. Durante esos meses, acompañé sistemáticamente las actividades realizadas por la Asamblea por Tierra y Vivienda, cobrando particular importancia el Foro Local de Acceso al Hábitat. En los siguientes apartados, se comenzará dando cuenta de algunas consideraciones teóricas que guían el análisis de las situaciones etnográficas recuperadas, para luego reconstruir los inicios de la Asamblea por Tierra y Vivienda, adentrándonos en las condiciones de posibilidad que permitieron su surgimiento así como también realizando una caracterización general de su dinámica de trabajo. Y, finalmente, se abordará el proceso que habilitó la conformación de un accionar colectivo a partir del surgimiento del Foro, buscando iluminar la complejidad que asume embarcarse en un hacer juntos(as) que tiene como objetivo principal garantizar el derecho a la vivienda digna y el derecho a la ciudad para vastos sectores sociales.

\section{Breves consideraciones teóricas}

A los fines de pensar la particularidades en torno a la Asamblea por Tierra y Vivienda, es que se consideran importantes las conceptualizaciones de Perelmiter (2011) puesto que iluminan como esa suerte de "experticia", anclada en un "saber profesional", se encuentra íntimamente vinculada con una "actitud militante" (Perelmiter, 2011). La autora, a partir de analizar el caso de los técnicos del Ministerio de Desarrollo Social, da cuenta de cómo la legitimidad de su trabajo descansa en la "posibilidad de deshacer las fronteras entre técnica, política y afecto" (2011: 163). Este análisis invita a pensar en el modo en que se funden esos tipos de saberes, o más precisamente, cómo ese saber profesional y técnico es movilizado desde la Asamblea para legitimarse en el escenario local y para establecer vinculaciones con las autoridades gubernamentales y con diversos -y heterogéneos- actores sociales.

En relación a ello, también interesa pensar la "dimensión pedagógica" desempeñada por la Asamblea en tanto procuraron definir, desarrollar y socializar "otras formas" de abordar la problemática habitacional a través de combinar diferentes conocimientos y prácticas. Partían de entender que su principal aporte radicaba en la producción de datos que permitían operan como pruebas técnicas para fundamentar demandas colectivas, habilitar espacios de negociación con el Estado y asesorar a la población respecto a requerimientos específicos de programas y políticas públicas (Manzano y Moreno, 2011). Pero además, intentaban 
Agustina Girado Análisis etnográfico del proceso de construcción de un accionar colectivo por el derecho a la vivienda y a la ciudad

constituirse en portavoces de la lucha por la tierra y vivienda mediante la denuncia, la visibilización de la temática, la elaboración de "propuestas" y el "apoyo" a vecinos en lucha.

No obstante, resulta preciso señalar que la "dimensión pedagógica" no tenía pretensión de definir formas moralmente correctas de decir y hacer, sino que procuraba atender a la "productividad política" que tenía la socialización de conocimientos, saberes y experiencias. En relación a lo que se mencionó anteriormente, los integrantes de la Asamblea no sólo pusieron a disposición un "saber profesional" sino que principalmente compartieron un compromiso político e ideológico con el trabajo y la lucha que desarrollaban diferentes actores sociales en materia habitacional a nivel local. Por este motivo, la utilización que hacían de un lenguaje científicotécnico, específico y racional, no buscaba anular el carácter eminentemente político del conocimiento, tensionándose aquellas representaciones que se esgrimen desde una supuesta eficiencia y neutralidad institucional. Se recuperaba a la ciencia y a la academia en tanto resultaba "estratégico" para hacerse de una capacidad diferencial y legitimada en pos de intervenir en el abordaje y gestión de la problemática habitacional, pero explicitándose la necesidad de complejizar y tensionar ese conocimiento a partir de los discursos y prácticas de los sujetos, histórica y desigualmente situados.

Sumado a ello, otro aspecto que desde la Asamblea se advirtió como estratégico y necesario fue el generar acciones colectivas con otras agrupaciones de la ciudad en pos de tener una comprensión más acabada de la problemática, y avanzar en la confección de modos de contacto, discusión y trabajo desde y contra el Estado (4) (Manzano, 2013a; Lazar, 2013), visualizado como un actor central en lo que hace a la gestión de la problemática habitacional. Para ello organizaron un Foro Local de Acceso al Hábitat, experiencia que posibilitó que diferentes actores pudieran pensarse y reconocerse "juntos" practicando un reclamo en común. En este sentido, el Foro buscó producir, entre las diferentes agrupaciones sociales y políticas que participaron activamente, un accionar político colectivo que no negara las experiencias particulares de trabajo y lucha sino que fueran recuperadas para, en un primer momento, legitimar su compromiso y experiencia con la problemática habitacional; para luego convertirse en un interlocutor -reconocido- del Estado, haciéndose eco de los reclamos y acciones de vecinos de diferentes barrios de la ciudad.

En relación a ello, resultan centrales en el presente artículo los aportes de Fernández Álvarez (2016) respecto al sentido y el carácter de lo colectivo, conceptualizándolo como un "hacer juntos(as)", el cual resulta contingente, contradictorio, fluido, parcial y muchas veces trunco, ponderándose los procesos por sobre los resultados, la creatividad por sobre la racionalidad y la producción por sobre la circulación.

Question, Vol. 1, N. ${ }^{\circ}$ 64, octubre-diciembre 2019. ISSN 1669-6581

Instituto de Investigaciones en Comunicación | Facultad de Periodismo y Comunicación Social | Universidad Nacional de La Plata La Plata | Buenos Aires | Argentina

Página 5 de 24 
Agustina Girado Análisis etnográfico del proceso de construcción de un accionar colectivo por el derecho a la vivienda y a la ciudad

Comienzo por el verbo que da contenido a la propuesta. Hacer, que más bien debería anunciarse en gerundio, haciendo, tiene la intención de enfatizar el carácter contingente y fluido de esas prácticas. El continuum de aquello que se produce en ese hacer. Donde lo que importa es la experiencia de estar viviendo y haciendo (....) Dejemos un momento el verbo para detenernos en el término que adjetiva la formulación propuesta. Juntos (as) tiene la intención de reconocer ante todo que lo colectivo no comprende, engloba ni condensa aquello que es del orden de lo individual, heterogéneo, plural (...) Esta formulación nos invita a deshacernos definitivamente de una mirada que parta del individuo -y por lo tanto focalizada en las motivaciones como sumatorias- para explicar experiencias que son necesariamente colectivas centrando nuestra atención en las relaciones incluyendo los afectos y las emociones-y las condiciones -social e históricamente definidasque las hacen posible (2016:16-17).

El enfoque que propone la autora permite afirmar que lo "colectivo" de ningún modo puede ser pensado como algo dado, siendo necesario explorar empíricamente no sólo las condiciones de posibilidad que habilitan la generación de un accionar colectivo, sino también cómo sus formas, dinámicas y contornos se construyen, confrontan, negocian, alteran e inclusive se disuelven en el hacer cotidiano. Pero además, la autora propone una mirada centrada en los procesos y en la atención a las relaciones de dominación en pos de comprender tanto los límites que se le imponen a las acciones de las personas cuanto el carácter creativo de las resistencias.

La experiencia de trabajo que se encarnó desde la Asamblea y posteriormente desde el Foro ilumina respecto a particulares formas de construir un accionar político colectivo, ponderándose aquello que se produce justamente en el propio andar, lo cual implica atender a los procesos, a los "triunfos" y los "fracasos" en la concreción de ciertos objetivos, y a las tensiones y los consensos generados respecto a las formas "correctas" de hacer y construir ciudad (Lacarrieu et. al, 2011). La diversidad de pertenencias e involucramientos simultáneos de los actores sociales (Rosa, 2011) que comenzaron a trabajar conjuntamente, posibilitó articular diversos experiencias, conocimientos y saberes -territoriales, académicos y políticos- que se fueron reactualizando en el curso de sus acciones, y que fueron relevantes en la configuración de los procesos de interacción social con los diferentes niveles del Estado y la ciudadanía en general. Asimismo, el presente trabajo sugiere la necesidad de producir conocimiento en relación a lo urbano en escala media en tanto ese "medianidad" opera en los modos de hacer y vivir la ciudad (Cravino, 2018; Bachiller, 2015; Gravano et.al, 2015). Si bien el abordaje de la "medianidad" resulta de un creciente interés dentro de las Ciencias Sociales en general, goza de relativa vacancia en lo que concierne a la producción antropológica a nivel nacional. Y esto resulta llamativo si se consideran los datos del censo 2010 puesto que Argentina cuenta con 57

Question, Vol. 1, N. ${ }^{\circ}$ 64, octubre-diciembre 2019. ISSN 1669-6581

Instituto de Investigaciones en Comunicación | Facultad de Periodismo y Comunicación Social | Universidad Nacional de La Plata La Plata | Buenos Aires | Argentina

Página 6 de 24 
Agustina Girado Análisis etnográfico del proceso de construcción de un accionar colectivo por el derecho a la vivienda y a la ciudad

ciudades medias cuya población estimada es de 50.000 a 5000.000 habitantes; y en lo que concierne a la provincia de Buenos Aires -dividida en 135 municipios- las ciudades cabeceras oscilan entre los 1.000 y los 600.000 habitantes, con la única excepción de La Matanza que supera el millón de habitantes.

Resulta preciso decir que si bien la categoría de "ciudad media" o "intermedia" suele establecerse a partir de indicadores estructurales y de funcionalidad, en un rango poblacional amplio que abarca desde los 50.000 a los 500.000 habitantes, diversas investigaciones han generado aportes a la consideración y comprensión de las dinámicas simbólicas que constituyen la especificidad de estos centros urbanos (Gravano et.al, 2015). En el caso de estudio, el carácter medio de la ciudad de Tandil advierte respecto a cómo ciertos imaginarios vinculados, por un lado, con la "negación" de la problemática habitacional local en tanto se pondera positivamente que la ciudad no cuenta con elevados índices de desocupación y pobreza ni tampoco tiene presencia de determinados fenómenos de informalidad urbana (como por ejemplo villas miseria); y, por el otro, con aspectos que hacen a la escala de la trama de relaciones, que suele expresarse bajo representaciones tales como "acá nos conocemos todos", operan en las formas pensar, construir y gestionar la problemática habitacional de Tandil, y particularmente permiten comprender las estrategias de trabajo y lucha desplegadas por la Asamblea y el Foro en pos de generar y garantizar un accionar colectivo que fuese legitimado por el Estado y la ciudadanía en general, y que permitiese avanzar en la reformulación de políticas de tierra y vivienda.

\section{Los inicios del trabajo de campo y el surgimiento de nuevos actores colectivos}

A fines de octubre de 2013 se originó la Asamblea por Tierra y Vivienda. Su conformación fue a consecuencia de un desalojo que sufrieron un grupo de familias en "La Movediza" en septiembre de ese año, "barrio mancha" (Gravano, 2005) de la ciudad que tiene la particularidad de albergar uno de los emblemas identitarios de Tandil (5), al mismo tiempo que condensa el imaginario social de que allí las ocupaciones de casas y de terrenos "se volvieron moneda corriente" durante los últimos años.

Quienes participaban principalmente de la Asamblea eran docentes y estudiantes de las carreras de Trabajo Social e Historia que se dictan en la UNICEN, los cuales desde hacía varios años realizaban un trabajo territorial en el mencionado barrio. Desde su aparición, la Asamblea expresó públicamente la necesidad de luchar por la concreción del derecho a la vivienda y el derecho a la ciudad para vastos sectores sociales, entendiéndolos como derechos diferenciados. El garantizar el derecho a una vivienda digna no implica que de manera 
Agustina Girado Análisis etnográfico del proceso de construcción de un accionar colectivo por el derecho a la vivienda y a la ciudad

automática también se garantice el derecho a la ciudad, entendiendo a este último como "un derecho de derechos" ya que contempla el derecho a la centralidad, a la participación política, al medio ambiente, al conjunto de servicios urbanos, entre otros (Thomasz, 2013).

La Asamblea se reunía semanalmente en un espacio cultural perteneciente a la UNICEN. Gran parte de las reuniones giraban en torno a situaciones de desalojos que sufrían vecinos de la ciudad, acompañándose a las familias afectadas en sus reclamos y acciones. Esto era básicamente ponerlos en contacto con abogados y defensores públicos; acompañarlos a reuniones con diferentes organismos estatales; y gestionarles a través de funcionarios locales y provinciales el acceso a diferentes programas que les permitiesen, en virtud de sus ingresos, acceder a préstamos para la construcción y/o mejoramiento de sus viviendas. En este punto, y atendiendo a la medianidad de la ciudad, resultaba fundamental la participación de dos trabajadoras sociales con una extensa trayectoria laboral a nivel local en tanto posibilitaba hacerse uso del "recurso vínculo"; es decir, valerse de relaciones sociales generadas previamente en pos de solicitar ayuda y tramitaciones, acceder a ciertos funcionarios y políticos y sortear instancias burocráticas, aspectos que muchas veces resultaban cruciales de cara a los objetivos de intervención que se planteaba la Asamblea.

Desde la primera reunión a la que asistí quedó explicitada la necesidad de adquirir herramientas jurídicas-técnicas que permitieran afrontar la problemática habitacional imperante, por este motivo se visualizaba a la Ley Provincial de Acceso Justo al Hábitat N 14.449 como una herramienta jurídica estratégica para fundamentar demandas colectivas y habilitar espacios de negociación con el Estado. Asimismo, esta Ley le otorga un rol fundamental a la participación de la sociedad civil en la planificación de proyectos que busquen facilitar el acceso a la tierra y mejorar las condiciones de habitabilidad, principalmente para los sectores de medios y bajos ingresos (CELS, 2016).

A medida que transcurrían los meses y se incrementaban las demandas de vecinos que se acercaban a la Asamblea en busca de ayuda y asesoramiento en materia habitacional, se comenzó a visualizar la necesidad de trabajar conjuntamente con otras agrupaciones, puesto que se sentían desbordados. Como refirió un integrante,

\footnotetext{
"cuánto más somos, más aprendemos a defendernos, todos los martes surgen más quilombos y vamos viendo cómo hacemos porque no tenemos recursos, tratamos de ayudar a los vecinos de acuerdo a lo que sabemos y vamos aprendiendo, pero necesitamos ampliar la lucha, sumar otras agrupaciones".
}

Question, Vol. 1, N. ${ }^{\circ}$ 64, octubre-diciembre 2019. ISSN 1669-6581

Instituto de Investigaciones en Comunicación | Facultad de Periodismo y Comunicación Social | Universidad Nacional de La Plata La Plata | Buenos Aires | Argentina

Página 8 de 24 
Agustina Girado Análisis etnográfico del proceso de construcción de un accionar colectivo por el derecho a la vivienda y a la ciudad

Así fue que los miembros de la Asamblea comenzaron a pensar en proyectos de trabajo que convocaran a otras agrupaciones. La particularidad de ser un espacio conformado por estudiantes y docentes universitarios jugó un rol fundamental en esas proyecciones. Entre las opciones "ganó" la propuesta de realizar el I Foro Local de Acceso al Hábitat, entendiendo que permitiría articular acciones de formación, debate e intercambio de experiencias entre diferentes organizaciones y ciudadanía en general, lo que además posibilitaría profundizar en la discusión pública, avanzar en la construcción de un diagnóstico de situación y en la elaboración de propuestas en materia habitacional. Sumado a ello, ese espacio se pensó financiar a través de la presentación a la convocatoria anual del Programa Nacional de Voluntariado Universitario (6), cuyo espíritu es atender a proyectos que reflejen particulares inquietudes y demandas de la población, sumado a que le otorgaría un marco de formalidad.

Si bien el proyecto logró presentarse en la convocatoria del voluntariado no fue aprobado, situación que igualmente motivó a incrementar los esfuerzos para poder concretarlo. El Foro se proyectaba como un espacio que debía continuar en el tiempo a partir de lograr propiciar un trabajo en conjunto; esta proyección obligaba a delinear un "Reglamento Interno del Foro Local de Acceso al Hábitat". En dicho documento se justificaba la importancia de generar el mencionado espacio a través de la recuperación de diferentes normativas respecto al derecho a la ciudad y a la vivienda digna (7); como así también se explicitaba que debía prever diferentes instancias de trabajo que posibilitaran articular el acceso a la información, la discusión y la toma de decisiones. De este modo, se establecían tres instancias complementarias de trabajo: encuentros plenarios del Foro Local de Acceso al Hábitat; comisiones sobre ejes de trabajo del Foro Local de Acceso al Hábitat y reuniones de la Comisión Coordinadora.

Después de transcurridos varios meses de arduo trabajo para los integrantes de la Asamblea, el 5 de septiembre de 2014 se logró realizar el I Foro Local de Acceso al Hábitat. En el mismo participaron vecinos de diferentes barrios de la ciudad y representantes de diversas organizaciones y partidos políticos, quienes expresaron sus inquietudes, problemáticas y acciones realizadas en pos del cumplimento de los mencionados derechos. Todos resaltaron como positivo que se creara un espacio de encuentro y debate, siendo el desafío sostenerlo en el tiempo puesto que resultaba una problemática transversal a los diferentes actores sociales. Teniendo en cuenta la diversidad de ejes que surgieron, y luego de concretarse a la semana siguiente la $1^{\circ}$ reunión de la Comisión Coordinadora, se acordó trabajar principalmente en dos de ellos: elaborar una ordenanza de adhesión a la Ley provincial № 14.449 de Acceso Justo al Hábitat y realizar un Diagnóstico Integral del acceso al hábitat (8) en la ciudad, aspectos que motivaban y justificaban la conformación de un accionar colectivo.

Question, Vol. 1, N. ${ }^{\circ}$ 64, octubre-diciembre 2019. ISSN 1669-6581

Instituto de Investigaciones en Comunicación | Facultad de Periodismo y Comunicación Social | Universidad Nacional de La Plata La Plata | Buenos Aires | Argentina

Página 9 de 24 
Agustina Girado Análisis etnográfico del proceso de construcción de un accionar colectivo por el derecho a la vivienda y a la ciudad

Un aspecto central del accionar de la Asamblea y del Foro es que permitió atender al carácter construido del problema habitacional. Es decir, en una ciudad que se concibe desde los sectores hegemónicos como "soñada" y "pujante", el acceso al suelo urbano y a la vivienda no se visualizaba como un problema -de primer orden- que entrara dentro de la competencia del gobierno local, atribuyéndose la responsabilidad política, por cuestiones presupuestarias y de competencia, al Estado Provincial y Nacional.

No obstante, la aparición pública de la Asamblea y el Foro, y posteriormente de otros actores colectivos, posibilitó interpelar esta representación, evidenciando y redefiniendo la existencia de una problemática habitacional a nivel local que requería ser atendida. Por este motivo, se consideran pertinentes los aportes de Gusfield (2014) ya que permiten, sin dejar de contemplar el lugar de las condiciones estructurales, centrar la mirada en el proceso de producción social y político que habilita a que particulares eventos y datos, en determinados contextos sociohistóricos, sean construidos por los propios actores sociales como un problema, a partir de elaborar motivos y justificaciones que lo legitiman, de construir "culpables" y establecer un plan de acción para llevar adelante demandas y reclamos a partir del despliegue, en la arena pública, de diversos procesos escenográficos, dramáticos y argumentativos.

Otro aspecto que se desprende de la creación del Foro se vincula a la certeza de sus integrantes respecto a que el Estado dialoga y negocia con individuos en tanto representantes de colectivos (Lazar, 2008), y que la legitimidad de su reclamo descansaría en la recuperación del trabajo territorial que realizaban y en la construcción de datos científicos-académicos. Ese proyectarse juntos implicó continuas tensiones, negociaciones y acuerdos respecto a las formas "correctas" y "deseables" de relacionarse y disputar con el Estado, de gestionar el acceso al suelo urbano y a la vivienda, y de hacer públicas sus demandas atendiendo a las particularidades sociales, económicas y políticas de la ciudad de Tandil (Girado, 2018). Por este motivo, en el próximo apartado se recuperará un episodio de toma de terrenos e intento de desalojo en el barrio Villa Cordobita, evento que no sólo interpeló el accionar, la representatividad y los tiempos del foro, sino que también permitió reflexionar respecto a las particularidades que asume la problemática habitacional a nivel local de cara a la construcción de futuras acciones y proyectos.

El proceso de construcción de un accionar colectivo: tensiones, acuerdos y proyecciones

En octubre de 2014 se produjo un intento de desalojo en el barrio -informal-(9) de Villa Cordobita, localizado próximo al centro de la ciudad y que tiene la particularidad de emplazarse 
Agustina Girado Análisis etnográfico del proceso de construcción de un accionar colectivo por el derecho a la vivienda y a la ciudad

sobre el faldeo serrano de Tandilia, motivo por el cual -en los últimos años- los terrenos que allí se localizan han sido sobrevalorados por el mercado inmobiliario ya que resultan atractivos para el desarrollo de proyectos urbanísticos. Fue en el marco de un proyecto de voluntariado que se realizó trabajo de campo con vecinos y agrupaciones sociales de Villa Cordobita, quienes mencionaron que el barrio surgió en el año 2006 a partir de la ocupación de tierras pertenecientes a la empresa Tandilia S.A., la cual quebró en 1963, existiendo una suerte de "vacío urbano" respecto a dichos terrenos ya que no fueron expropiados de manera inmediata por el gobierno municipal.(10) Sin embargo, posteriormente se radicaron en el barrio más familias pertenecientes tanto a sectores populares cuanto a clases medias, dando lugar a una diversas de situaciones producto de las estrategias desplegadas para acceder al suelo urbano ya sea por ocupación, compra-venta formal e informal de tierras y por la realización de un proyecto urbanístico PRO.CRE.AR.

Ahora bien, en la última década se han sucedido diferentes situaciones de desalojos (11) en el barrio involucrando a un número variable de familias. No obstante, en el presente artículo se referirá a un caso en particular, el cual interpeló el accionar del Foro y la Asamblea. En este sentido, en octubre de 2014 los medios de comunicación dieron a conocer el intento de desalojo 4 familias que estaban comenzando a construir sus viviendas en terrenos que pertenecerían a la empresa Tandilia. Luego del intento de desalojo que no pudo concretarse, los integrantes de la Asamblea se pusieron en contacto con las personas implicadas. A partir del diálogo entablado, se supo que había un supuesto dueño que reclamaba la propiedad de los terrenos ocupados pero que carecía de documentos que probaran su titularidad, y que una funcionaria municipal resultó ser la testigo de la causa. Sumado a ello, las familias implicadas dieron cuenta de que en el barrio había varios terrenos comprados por funcionarios de la gestión de Lunghi, advirtiendo sobre el manejo de información privilegiada por parte de los funcionarios para hacerse de suelo urbano. Estos elementos daban cuenta sobre la existencia de un entramado complejo de vínculos entre la política, redes de ilegalidad y el negocio inmobiliario en lo que hace al acceso al suelo urbano (CELS, 2016).

En la búsqueda por revertir el posible desalojo, las 4 familias fueron asesoradas y acompañadas por Mario y Gisela, (12) dirigentes de la agrupación política y sindical "Corriente Clasista y Combativa (CCC)" (13), quienes no sólo viven en el barrio por lo cual se consideran un "vecino más", sino que también desde hace varios años vienen realizando un trabajo territorial allí, puntualmente en lo que concierne a la regularización dominial de más de 60 familias. Estos dirigentes le solicitaron al Honorable Concejo Deliberante un pedido de investigación por "tráfico de influencias" de los funcionarios municipales, abogados y miembros de la justicia involucrados en el desalojo de las familias.

Question, Vol. 1, N. ${ }^{\circ}$ 64, octubre-diciembre 2019. ISSN 1669-6581

Instituto de Investigaciones en Comunicación | Facultad de Periodismo y Comunicación Social | Universidad Nacional de La Plata La Plata | Buenos Aires | Argentina

Página 11 de 24 
Agustina Girado Análisis etnográfico del proceso de construcción de un accionar colectivo por el derecho a la vivienda y a la ciudad

Desde la Asamblea se consideró correcto "acompañar" la lucha de las familias así como de otros vecinos ya que posibilitaba transparentar la problemática habitacional local; "acompañar" significaba no sólo "poner el cuerpo" en las reiteradas manifestaciones públicas organizadas por los vecinos y la CCC, sino también poner a disposición el conocimiento adquirido por sus profesiones, por sus reiterados contactos con organismos y funcionarios del Estado y por sus experiencias previas en desalojos en otros barrios de la ciudad.

Con el transcurrir de los días diversas organizaciones, muchas de las cuales conformaban la Comisión Coordinadora del Foro (Movimiento Evita, Víctor Jara, Patria Grande), se hicieron presentes a título personal en las reuniones diarias que llevaban a cabo las familias a desalojar, como así también emitieron comunicados en los diarios locales denunciando el accionar del Estado Municipal, que ante opciones habitacionales restringidas oscila entre acciones de indiferencia y acciones de hostigamiento y control punitivo. En ese clima de tensión, se propagaba constantemente el rumor de hacer efectivo el desalojo. No obstante, las especulaciones fundadas en la lucha y en un saber jurídico respecto al por qué no se podía llegar a realizar (cantidad de horas transcurridas desde la notificación, menores de edad en el lugar, funcionarios municipales implicados, etc.), habilitaron una serie de vínculos y acciones al interior del barrio que buscaron fortalecer el reclamo de las familias afectadas, y propiciar el apoyo de diversas agrupaciones para hacer visible el conflicto (Manzano, 2013).

Lo acontecido en Villa Cordobita en un primer momento interpeló a la Comisión Coordinadora del Foro puesto que las energías se debían depositar por un lado, en acompañar a los vecinos en su lucha e impedir un eventual desalojo y, por otro lado, seguir avanzando en los ejes establecidos como prioritarios. Después de haber pasado un mes del intento de desalojo, derivando en la radicación de una denuncia penal por "Asociación ilícita y tráfico de influencias" de funcionarios municipales, judiciales y abogados, la Asamblea por Tierra y Vivienda convocó a una reunión de la Comisión Coordinadora del Foro, invitándose a los dirigentes de la CCC y algunos de los vecinos de Villa Cordobita.

La reunión se desarrolló en la sede administrativa de la UNICEN. Quién comenzó la charla fue Mario, mencionando que el día lunes se habían manifestado en el Municipio participando de las sesiones del Concejo Deliberante, pidiéndose la Banca 21 (14) para denunciar la situación por la cual estaban atravesando los vecinos de Villa Cordobita. En esa oportunidad, le entregaron a cada bloque político un documento que elaboraron en donde se detallaba los pedidos históricos del barrio por la regularización de terrenos, la denuncia que recientemente habían radicado y las pruebas que disponían para acusar a ciertos funcionarios

Question, Vol. 1, N. ${ }^{\circ}$ 64, octubre-diciembre 2019. ISSN 1669-6581

Instituto de Investigaciones en Comunicación | Facultad de Periodismo y Comunicación Social | Universidad Nacional de La Plata La Plata | Buenos Aires | Argentina

Página 12 de 24 
Agustina Girado Análisis etnográfico del proceso de construcción de un accionar colectivo por el derecho a la vivienda y a la ciudad

municipales, “(...) entendemos que la denuncia judicial es un proceso clave... pero los tiempos que manejan ellos son muy diferentes a los tiempos que manejamos nosotros... lo legal es importante pero debemos estar generando conflicto político y mediático... debemos ir a los palos para que hablen de la corrupción". La otra dirigente que estaba presente, Gisela, remarcó que "el tema es la capacidad de movilización que se tenga aparte de los argumentos, así sí te dan bola para votar (...) tiene que haber agite grande”.

Lo mencionado por Mario y Gisela permite dar cuenta de las relaciones entre tiempo y política, o mejor dicho, de la importancia de atender al tiempo a los fines de establecer modos de contacto con el Estado (Manzano, 2013b). Mientras que para los dirigentes de la CCC se priorizaba la puesta de los cuerpos en la calle y el desarrollo de acciones beligerantes, generándose acontecimientos, acotados en el tiempo, pero de carácter más disruptivo que no sólo anunciaban la existencia de un conflicto sino que también producían vínculos con el Estado a partir de movilizar su estructura institucional, disputando aquel tiempo que se impone a través de formas burocráticas y que da cuenta de la dominación estatal; quienes integraban el Foro, por el contrario, entendían que en términos estratégicos debía priorizarse una agenda de trabajo con los funcionarios y políticos, lo cual implicaba continuas reuniones, presentación de documentación y utilización de instancias de orden legislativo, ya que ello permitiría alterar el curso de los procedimientos burocrático y habilitar diálogos que se sostuvieran en el tiempo. Ahora bien, más allá de los diversos ejes abordados por los mencionados dirigentes y las discusiones que generaron con el resto de los presentes, a continuación me centraré en lo que devino de la reunión una vez que se retiraron tanto los vecinos cuanto Mario y Gisela. Uno de los primeros aspectos que llamaron mi atención de aquella reunión fue el intento constante de los presentes por diferenciar el reclamo de los vecinos respecto del posicionamiento por parte de los dirigentes de la CCC, existiendo cierto énfasis en destacar la manipulación de los segundos hacia los primeros.

Como señala Frederic y Masson (2006), los representantes políticos se diferencian entre sí y definen su lugar en el campo político en virtud de la distribución de cualidades sociales y de mecanismos de reconocimientos entre actores que se encuentran asimétrica y simétricamente unidos entre sí. En relación a esto, en la reunión se hizo manifiesta la "mala" reputación con la que contaba la CCC, destacándose la existencia de una crisis de credibilidad respecto a la figura de sus dirigentes. Ese descreimiento y deslegitimación que realizaban las agrupaciones se vinculaba a una "mala" manera de hacer política en tanto sus referentes privilegiarían los intereses propios por sobre los de las personas (Quirós, 2011); inclusive les valió la acusación de realizar una política clientelista en virtud de la utilización que hacían de los recursos 
Agustina Girado Análisis etnográfico del proceso de construcción de un accionar colectivo por el derecho a la vivienda y a la ciudad

estatales. Asimismo, algunos miembros de las agrupaciones recuperaban eventos de un pasado reciente que daban cuenta de imaginaciones que vinculan a partidos políticos de izquierda con acciones de protesta y confrontación directa con el Estado, como era haber participado de acampes, marchas y toma de edificios públicos en la ciudad y en la Capital Federal, señalándose la necesidad de tejer otras vinculaciones con el Estado que no utilizaran como principal recurso la demostración situacional de fuerzas. Y porque además, en una ciudad como Tandil, este tipo de acciones no eran ni recurrentes ni deseadas, existiendo una suerte de presión moralizante de la ciudad sobre las prácticas y discursos que los actores sociales -de manera individual y/o colectivamente; cotidiana y/o extraordinariamentedesplegaban para garantizar el derecho a la vivienda y a la ciudad (Girado, 2018).

A modo de contraposición, los representantes de las agrupaciones presentes intentaban establecer una diferencia con esas formas inmorales de hacer política (Frederic, 2009) y, específicamente, discutían la participación que tuvieron algunos de los vecinos de Villa Cordobita en la reunión desarrollada, en tanto no hicieron uso de la palabra, siendo Mario y Gisela los que "hablaban por ellos". Este accionar vivenciado también en las reuniones que se realizaban al interior del barrio, permitía sustentar en los integrantes del foro la representación de los vecinos como sujetos -en cierta medida- "pasivos", "despolitizados" y "utilizados" por la CCC. Sumado a ello, el desarrollo de la reunión permitía advertir concepciones distintas respecto a las formas de participación; en términos generales se podría decir que la participación que se generaba al interior del Foro apuntaba a una dinámica horizontal y a la generación de acuerdos sobre la base de considerar qué resultaba más estratégico en términos políticos, a mediano y largo plazo, para consolidar vinculaciones con el Estado y para avanzar en la generación de políticas urbanas y habitacionales que permitiesen producir modificaciones en el modelo de ciudad imperante. Por este motivo, "renegaban" del accionar de la CCC ya que proponían una dinámica jerárquica de funcionamiento y no se propiciaba una "auténtica" participación de los vecinos, no dándoles lugar a que expresen sus posicionamientos y disidencias respecto a las formas de accionar.

Manuel (Integrante de la Asamblea por Tierra y Vivienda):- en la asamblea se ha planteado eso de querer escuchar la voz de los vecinos porque ellos (refiriéndose a los dirigentes de la CCC) se acaparan del discurso, de la discusión... porque son representantes del barrio Villa Cordobita pero... los que están ocupando y el resto de los vecinos ¿qué dicen?

Martín (Integrante de la Víctor Jara):- Los vecinos no hablaron hoy.

Manuel (Integrante de la Asamblea por Tierra y Vivienda):- son varias cosas, no hay que actuar con ingenuidad política pero tampoco hay que dejar de ver que sí es legítimo lo que se están planteando, sobre todo lo que refiere a la tenencia de la tierra...

Question, Vol. 1, N. ${ }^{\circ}$ 64, octubre-diciembre 2019. ISSN 1669-6581

Instituto de Investigaciones en Comunicación | Facultad de Periodismo y Comunicación Social | Universidad Nacional de La Plata La Plata | Buenos Aires | Argentina

Página 14 de 24 
Agustina Girado Análisis etnográfico del proceso de construcción de un accionar colectivo por el derecho a la vivienda y a la ciudad

Marcos (Integrante del Movimiento Evita):- incluso los hemos bancado a los vecinos estando la CCC, pero ellos han tenido la inteligencia de generar todo esto con la chapa de la CCC y los vecinos se desdibujan en todo este reclamo. En las asambleas no va un vecino más porque hablan una hora ellos, tal como pasó acá.

Prosigue hablado Marcos:- y yo que sé, cuando fuimos la otra vez un domingo pedimos que hablen los vecinos y nos dijeron todos que sí pero la realidad es que nos ganaron porque nos primeriaron, porque acompañaron, porque son los que están con ellos y bueno es legítimo el lugar que se ganaron pero también obtura la posibilidad de que también ellos construyan, que los vecinos construyan una alternativa de ellos.

Toma la palabra Manuel:- creo que lo legítimo es hacerle el apoyo a los vecinos hasta donde podamos y colaborar con lo que necesiten, poner en discusión también lo que nosotros creemos que habría que hacer como estrategia pero sabiendo que el conflicto ahí lo van a conducir ellos ¿me entendés? Y sabiendo que los medios no va a salir con un título que diga los vecinos de Villa Cordobita, va a salir un título que diga la CCC tal y tal cosa (...) igual no es porque la CCC les dice pongan la CCC, sino que para el Eco es mucho más fácil también vender eso.

Desde las agrupaciones sociales y políticas que integraban el Foro se recuperaba el trabajo social y territorial que realizaban en diferentes barrios de la ciudad en pos de dar cuenta de otro tipo de vinculaciones entre "la política/los políticos" y "los vecinos", teniendo presente que resultan aspectos imbricados y que en todo caso esta distinción es eficaz a los fines de pensar las formas de acción y participación colectivas (Frederic, 2009). En este sentido a través de la apelación a "lo social", a "lo territorial", se procuraba resaltar un accionar desinteresado, voluntario, un trabajo conjunto con los vecinos. Este último aspecto se visualizaba como crucial ya que entendían que eran ellos los que debían motorizar las acciones y discusiones respecto a cómo resolver problemáticas puntuales, y en todo caso la labor de las agrupaciones era acompañar la lucha, brindar herramientas y conocimientos para -en términos políticamente estratégicos- construir y gestionar las demandas y propiciar la generación de vinculaciones con diversos actores, oficinas y niveles del Estado. Sumado a ello, entendían que en la práctica política los beneficios personales no podían, ni debían, ser prioridad, buscándose una comprensión profunda de "la política" que lograra desbordar la satisfacción de ciertas necesidades básicas de los sujetos (Quirós, 2011; Ferraudi Curto, 2000).

En vinculación a lo mencionado, desde la perspectiva de los miembros de las agrupaciones presentes, la "ayuda" brindada por la CCC daba cuenta de un intento de capitalizar políticamente su intervención en el conflicto. Entendían que su reputación, catalogados desde vastos sectores como "quilomberos, oportunistas, vagos", deslegitimaba el reclamo de los

Question, Vol. 1, N. ${ }^{\circ}$ 64, octubre-diciembre 2019. ISSN 1669-6581

Instituto de Investigaciones en Comunicación | Facultad de Periodismo y Comunicación Social | Universidad Nacional de La Plata La Plata | Buenos Aires | Argentina

Página 15 de 24 
Agustina Girado Análisis etnográfico del proceso de construcción de un accionar colectivo por el derecho a la vivienda y a la ciudad

vecinos de Villa Cordobita. Por este motivo, en la reunión se buscó que éstos últimos proyectaran en el Foro un espacio en donde continuar su lucha junto a otros vecinos de la ciudad que estaban y/o atravesaron por situaciones similares.

En este sentido, se transparentaba la preocupación por construir un discurso unificado en relación al conflicto en Villa Cordobita que permitiera dar cuenta de las dificultades que también atravesaban otros vecinos de la ciudad. Se debía ser estratégico respecto a cómo se inscribía el conflicto en la agenda institucional y mediática en la búsqueda por hacer colectivo un reclamo que en principio aparecía vinculado a ciertas personas pero que atravesaba a vastos sectores sociales. En este punto los aportes de Cefaï (2002) resultan operativos para pensar cómo se construye la legitimidad de un reclamo. El autor afirma que en el "proceso de publicización" de una situación construida por los propios actores sociales como problemática, se requiere de "públicos" que reconozcan su legitimidad; éstos no sólo refieren a las personas que afecta directamente el problema sino también aquellas que están afectadas sin estar directamente implicadas en el asunto.

A los fines de ganar legitimidad y convocar a otros públicos se visualizaba como estratégico la adhesión a la Ley de Acceso Justo al Hábitat, debiendo "conquistarse" a través de articular adecuadamente tramitación con movilización (Manzano, 2013a). Por este motivo, se advertía sobre la importancia de respetar un "tiempo de aprendizaje" a los fines de apropiarse de un lenguaje jurídico-técnico contemplado tanto por la Ley como por otras políticas públicas -por ejemplo el Plan de Desarrollo Territorial de Tandil-, y de ese modo construir "un proyecto de adhesión contundente". Pero fundamentalmente se buscaba conseguir un logro político significativo que diera cuenta de la potencialidad de un hacer juntos(as), no dejándose llevar por los tiempos de ebullición que establecía el conflicto público en Villa Cordobita, ya que cuando un conflicto se inscribe en la esfera pública se ven involucrados nuevos actores sociales y se producen alteraciones en los tiempos de acción tanto del Estado como de los actores sociales movilizados. No debía resignarse la agenda de trabajo que se había confeccionado luego de la realización del Foro, siendo imprescindible revalorizar las energías, el trabajo cotidiano, el esfuerzo y el compromiso que requería el trabajo en conjunto.

María (Miembro de la Asamblea por Tierra y Vivienda):- ¿cómo haces para convocar a gente?, no por el planteo te diría... el tema es la CCC, quien te los acompaña (se ríe) eso es clave para mí (...) es un reclamo que además de ser justo es evidente y que tiene que ver con los vecinos de Villa Cordobita, lo tendríamos que encarar por eso lado (...) por ahora hemos quedado desdibujado y creo felizmente, porque dicen CCC y otras organizaciones (...).

José (Integrante del Movimiento Evita):- yo creo que al conflicto del desalojo sí hay que encontrarle una solución pacífica, no puede ser la de ir a prender gomas o armar (...) yo creo 
Agustina Girado Análisis etnográfico del proceso de construcción de un accionar colectivo por el derecho a la vivienda y a la ciudad

que esto es una puerta abierta para el debate de la nueva Ley Acceso Justo al Hábitat, a mí me parece mucho mejor regularizar la situación de los terrenos en Villa Cordobita, en Movediza, en Villa Aguirre y en todos los barrios antes que el conflicto de la pelea política que tienen ellos.

Martín (Integrante de la Víctor Jara):- Yo creo que hacer una movilización para un acto de pedido de transparencia no me parece necesario; me parece que en ese caso tendríamos que ir por algún camino institucional y para eso es una cuestión de estrategia, si vos caes al municipio a prender gomas si se quiere o con otra acción de resistencia te va peor. Ahora, en el otro caso la de la seguidilla de pedir la banca 21 no me parece (....) para mí una acción de choque no es lo correcto... hay que avanzar con la Ley de Acceso Justo al Hábitat como lo venimos haciendo.

Marcos (Integrante del Movimiento Evita):- Una impresión que tengo al escucharlos... se perdió la cuestión del desalojo, de la lucha... ellos ya no están reclamando digamos la urbanización, la regularización. O sea, el caballito de batalla de ellos es esta cuestión del reclamo de esta investigación judicial (...) No nos apuremos, participemos de este espacio de formación de conocer bien la ley, que cosas son aplicables a Tandil, tener un dato más certero de cómo es la situación en Tandil.

Manuel (Integrante de la Asamblea por Tierra y Vivienda):-claro... creo que la idea general es no quemar lo que estamos laburando antes porque nos vamos arrepentir... es un momento muy sensible porque ellos (refiriéndose a la CCC) han generado toda una cuestión ahí de ebullición que desdibujan las discusiones que venimos dando y el sentido que le queremos dar a la construcción colectiva.

Los fragmentos recuperados, advierten respecto a cómo las agrupaciones que integraban la Comisión Coordinadora buscaban trascender aquellos reclamos y acciones vinculadas a demandas y conflictos puntuales, a los fines de habilitar un debate respecto a cómo generar en el marco del Foro relaciones, pertenencias y compromisos político-ideológicos que habilitaran a pensar y transformar aspectos estructurales de la ciudad. Se debía poder articular lo urgente con lo importante, ir un poco "más allá" en las discusiones respecto a la ciudad que se deseaba construir, ampliando el horizonte de los posibles.

El carácter proyectual de ese "hacer juntos(as)" (Fernández Álvarez, 2016) se tornó un elemento importante en la narrativa del Foro. En el ejercicio constante de pensar otras formas de abordar y de brindar respuestas a la problemática habitacional, se destacaba la necesidad de debatir sobre el proyecto municipal de ciudad que tenía -y aún tiene- la gestión de Lunghi, en tanto que privilegia un diseño urbano basado en políticas de embellecimiento y estética citadina (murales, mejoramiento de plazas públicas, cambios en la luminaria de la ciudad, intervenciones artísticas, creación de nuevos senderos turísticos, entre otros aspectos), 
Agustina Girado Análisis etnográfico del proceso de construcción de un accionar colectivo por el derecho a la vivienda y a la ciudad

abonando a su slogan de "lugar soñado". Sin embargo, la gestión de la ciudad invisibiliza la otra cara de la "belleza", ya que en las últimas décadas se han profundizado las desigualdades en torno al valor de uso de la ciudad (Girado, 2018).

En este contexto, las agrupaciones que integraban la Comisión Coordinadora buscaban inscribir en la agenda institucional y mediática la problemática habitacional a partir de señalar la existencia de "otra ciudad que no es precisamente la soñada por el Intendente". La legitimidad de sus reclamos descansaba en la recuperación del trabajo territorial, de datos científicosacadémicos y de un accionar colectivo que visibilizaba las condiciones socio-históricas que lo hicieron posible. Fue en la puesta a andar del espacio del Foro, que estas agrupaciones se iniciaron en un proceso creativo -y controvertido- que cotidianamente buscaba producir juntos(as) una serie de criterios y definiciones respecto a cuáles serían las formas "correctas" de gestionar la problemática habitacional en virtud de sus posicionamientos políticosideológicos particulares, y principalmente cuál sería esa ciudad que se buscaba construir para que pudiera ser apropiada y disfrutada por vastos sectores sociales.

\section{Reflexiones finales}

El desafío que tuvo la experiencia del Foro, motorizada por la Asamblea por Tierra y Vivienda, fue la búsqueda por generar un trabajo en conjunto con otras agrupaciones y vecinos que estuvieran abocados a la temática del hábitat. En este marco, diversos actores tuvieron que pensarse y reconocerse "juntos”, practicando un reclamo en común. La articulación de variadas trayectorias posibilitó entretejer discursos, afectos, acciones, intereses y proyectos que buscaban intervenir en el curso de la historia. No obstante, esta articulación supuso el desafío inevitable de negociar los sentidos, efectos y proyectos asociados a ese estar y hacer "juntos(as)"; articulación que siempre resulta parcialmente estructurada y estructurante, histórica y transitoria, producto del movimiento y la conexión (Fernández Álvarez, 2016).

En este sentido, el Foro posibilitó consolidar un accionar colectivo que buscó principalmente avanzar en la adhesión municipal a la Ley de Acceso Justo al Hábitat, trabajando en el "mientras tanto" con demandas concretas y conflictos que presentaban vecinos de la ciudad; adhesión que finalmente se consiguió el 27 de agosto de 2015 a través de su aprobación por unanimidad en el Concejo Deliberante. Luego de conseguirse ese logro político se buscó seguir trabajando en la generación de datos que permitieran "medir" y "dimensionar" la problemática habitacional local, para ello el aporte de profesionales y grupos de investigación de la UNICEN se visualizaba como un aspecto fundamental. Al mismo tiempo se imaginaba y se proyectaba 
Agustina Girado Análisis etnográfico del proceso de construcción de un accionar colectivo por el derecho a la vivienda y a la ciudad

generar vinculaciones con otras universidades, centros de investigación y organizaciones, ampliando las discusiones y la red de relaciones.

Por un par de meses más se continuó trabajando juntos(as), no obstante la situación se fue desdibujando principalmente a raíz de que la Asamblea dejó de funcionar sistemáticamente, lo cual ocasionó que el Foro también dejara de funcionar puesto que los que mayormente motorizan los encuentros y reuniones eran los integrantes de la Asamblea. En este sentido, podría sostenerse que la participación de sus integrantes no escapó al carácter contingente, fluido y móvil de los vínculos y las personas; el principal motivo por el cual dejó de funcionar la Asamblea se vincula a que sus integrantes eran mayoritariamente estudiantes universitarios, priorizando el desarrollo de sus carreras. Ante la merma de muchos de sus integrantes se hizo imposible garantizar la continuidad del espacio ya que no se disponía de recursos humanos, ni materiales, para hacer frente a las demandas de los vecinos y poder concretar las acciones proyectadas. Y, en lo que respecta a la participación de las agrupaciones políticas en el Foro, se detecta como principal obstáculo -que no se pudo sortear- la imposibilidad por articular sus propias agendas de trabajo con la del Foro, sumado a que su prioridad era participar en el desarrollo de los procesos electorales que acontecieron a los pocos meses se originarse el Foro.

En virtud de lo narrado podría afirmarse que la experiencia de construir un accionar colectivo resultó trunca, lo cual es cierto. No obstante, su carácter controvertido y el hecho de que no se pudiera mantener a largo tiempo no niega la potencialidad y la productividad política que tuvo la experiencia de ese hacer juntos(as). Siguiendo a Fernández Álvarez resulta preciso “(...) reivindicar el potencial analítico -y, por qué no, político- de las situaciones aparentemente truncas en el estudio de la política colectiva" (2016:25), por este motivo no sólo cobra centralidad la concreción de ciertos objetivos sino más bien el transcurrir mismo de los diversos actores sociales.

En un contexto socio-histórico de creciente conflictividad social respecto a las dificultades que vastos sectores experimentaban a la hora de satisfacer el derecho constitucional a una vivienda digna y el derecho a la ciudad, fue posible comenzar a tejer tramas políticas que habilitaron procesos de acción y relación entre actores diversos. El acompañar etnográficamente ese proceso posibilitó advertir la relevancia que se le sigue otorgando al Foro en tanto un "momento de ruptura" en el abordaje y tratamiento de la problemática habitacional a nivel local, tal es así que diversas agrupaciones comenzaron a brindarle un papel preponderante en sus agendas de trabajo a la lucha por el acceso al suelo urbano, la vivienda y la ciudad. La experiencia de trabajo que se encarnó desde la Asamblea y posteriormente desde el Foro hizo visible las potencialidades de un accionar colectivo que permite articular 
Agustina Girado Análisis etnográfico del proceso de construcción de un accionar colectivo por el derecho a la vivienda y a la ciudad

diferentes trayectorias de vida, de trabajo y de militancia en la búsqueda por ampliar el horizonte de los posibles en materia habitacional; al tiempo que permite advertir la centralidad que adquieren los procesos de participación social en pos de garantizar el acceso justo al hábitat.

Notas

(1) El Intendente Radical Miguel Ángel Lunghi fue electo en cinco oportunidades (2003-2007, 2007-2011, 2011-2015, 2015-2019, 2019-2023).

(2) La marca ciudad constituye una "estrategia de gestión de imagen desarrollada desde hace algunos años en distintas ciudades del mundo, y que recientemente comenzó a ser utilizada por municipios de Argentina. (...) La Marca-Ciudad se destina principalmente a potenciar las capacidades de los territorios, desplegar sus ventajas competitivas y posicionarlos nacional e internacionalmente, objetivo que, en general, se persigue a partir de la promoción del turismo con la pretensión de generar externalidades y efectos multiplicadores a futuro." (Calvento y Colombo, 2009: 263).

(3) El autor se refiere con la mencionada denominación a aquellos barrios "manchados" por ciertos estigmas urbanos como son la delincuencia, la inseguridad, la droga y la juventud conflictiva, entre otros.

(4) En el transcurso del artículo recurrentemente se hará hincapié en el gobierno local, categoría que posibilita pensar al Estado en su dimensión vívida, histórica y temporal; además resultó un término utilizado por los interlocutores, a partir del cual refieren a su experiencia cotidiana de aquello de se suele uniformizar y abstraer en términos de "Estado" (Quirós, 2011). (5) Allí se emplaza la réplica de la Piedra Movediza, mole de granito de más de 300 toneladas de peso, de 6 metros de altura y casi 8 de largo, que se mantenía en equilibrio sobre un pequeño punto de apoyo, el cual se cayó en febrero de 1912.

(6) El Programa Nacional de Voluntariado Universitario depende del Ministerio de Educación y comenzó a implementarse en marzo de 2006.

(7) Constitución Nacional, Artículo 14 bis; Constitución de la Provincia de Buenos Aires, Artículo 36, inciso7; Constitución de la Ciudad Autónoma de Buenos Aires, Articulo 31; el pacto de San José de Costa Rica; y la carta mundial por el derecho a la ciudad; el Plan de Ordenamiento Territorial de Tandil, Ley provincial №14.449 de Acceso Justo al Hábitat.

(8) El concepto de hábitat refiere a un entramado complejo en el cual la vivienda es un elemento central pero no el único puesto que implica "el acceso universal a la tierra, a la vivienda y a las infraestructuras básicas y los equipamientos sociales, los servicios y los 
Agustina Girado Análisis etnográfico del proceso de construcción de un accionar colectivo por el derecho a la vivienda y a la ciudad

espacios de trabajo y producción en un marco de respeto de los rasgos culturales y simbólicos de la comunidad y de la preservación del ambiente, según las particularidades del medio urbano y del rural(...)" (Consenso Nacional para el Hábitat Digno, 2015).

(9) La informalidad urbana implica dos formas de transgresiones, por un lado, respecto a los aspectos dominiales (falta de títulos de propiedad y/o contratos de alquiler); y, por el otro, al proceso de urbanización (incumplimiento de las normas de construcción de la ciudad). Resulta necesario remarcar que la condición de informalidad urbana no es exclusiva de los sectores populares, ya que diversas formas de residencia características de las clases medias-altas resultan informales (Clichevsky, 2009).

(10) El gobierno municipal de Lunghi en el año 2006 le gana un juicio sobre apremios a la empresa Tandilia, esto lo habilitaba a que pudiera reclamar sobre los lotes (450 aproximadamente). No obstante, no fue hasta el 2015 que el gobierno municipal, y como consecuencia de reclamos varios vecinos de Villa Cordobita, aprueba 3 medidas por Concejo Deliberante: expropiación de 450 lotes pertenecientes a la empresa Tandilia; se le solicita al Registro de la Propiedad del Inmueble de la Provincia de Buenos Aires el listado de titulares del dominio de los terrenos pertenecientes a la empresa; y se establece la realización de un censo para determinar el números y las características de la población afectada que reside en terrenos de la empresa.

(11) En septiembre de 2015, 130 familias lideradas por Mario y Gisela (CCC) ocuparon terrenos en Villa Cordobita, pertenecientes a la empresa de Tandilia. Este hecho adquirió una relevancia sustancial en la agenda institucional y mediática puesto que la ocupación fue de carácter colectiva, organizada y pacífica; siendo la ocupación más importante que aconteció en la ciudad por el número de familias implicadas. Luego de la ocupación, se dio curso a la intervención de la justicia a partir de la denuncia realizada por un grupo de vecinos que declaraban ser los legales propietarios de esas tierras, alegando usurpación; sumado a la denuncia penal que interpuso el Intendente Lunghi para con los responsables de la ocupación Mario y Gisela- por delitos en contra del orden público. Luego de varios meses de conflicto, existiendo una orden de desalojo, en diciembre de 2015 las 130 familias que ocupaban habían abandonado pacíficamente los terrenos.

(12) Los nombres de las personas que integran las diferentes agrupaciones sociales y políticas fueron modificados con el objetivo de preservar su identidad.

(13) Esta agrupación -política y sindical- impulsada por el Partido Comunista Revolucionario, a nivel local era identificada por otras agrupaciones como "los piqueteros de Lunghi". A través de esa denominación se intentaba señalar la "buena relación" que inicialmente el gobierno local tuvo con la CCC en tanto no cuestionaban sus acciones beligerantes cuando se trataba de 
Agustina Girado Análisis etnográfico del proceso de construcción de un accionar colectivo por el derecho a la vivienda y a la ciudad

reclamos con otros niveles del Estado, que además representaban a otro signo político (Frente para la Victoria). Sin embargo, la relación se tensionó -en 2014- cuando el gobierno de Lunghi decidió recortarle la entrega de recursos.

(14) La Banca 21 es una herramienta creada por decreto del Concejo Deliberante de Tandil para permitir a ciudadanos, comisiones barriales e instituciones diversas exponer un proyecto, tal y como si lo presentara un legislador, para luego ser evaluado por las comisiones correspondientes, que lo canalizan hasta que es tratado sobre tablas.

\section{Bibliografía}

Bachiller, S. (2015). (ed.). Tomas de Tierras y dificultades de acceso al suelo urbano en la Patagonia central. Rio Gallegos: Universidad Nacional de la Patagonia Austral.

Calvento, M. y Colombo, S. S. (2009). La Marca-Ciudad como herramienta de promoción turística. ¿Instrumento de inserción nacional e internacional? Estudios y Perspectivas en Turismo, Vol. 18, Núm. 3, 262-284.

Centro de Estudios Legales y Sociales. (2016). Derechos humanos en la Argentina Informe 2016. Buenos Aires: Siglo Veintiuno Editores. Recuperado de: https://www.cels.org.ar/web/wp-content/uploads/2016/12/IA2016-CELS-1.pdf

(2015). Derecho a la tierra y a la vivienda, aportes al consenso nacional para un hábitat digno. Ciudad Autónoma de Buenos Aires: CELS. Recuperado de: https://consensohabitar.org.ar/pdf/derecho-a-la-tierra-y-la-vivienda.pdf

Clichevsky, N. (2009). Algunas reflexiones sobre la informalidad y regularización del suelo urbano. Bitácora, 1 (14), 63-88. Recuperado de: https://revistas.unal.edu.co/index.php/bitacora/article/view/18508

Cravino, M. C. (2018). (Org.). La ciudad (re)negada. Aproximaciones al estudio de asentamientos populares en nueve ciudades argentinas. Los Polvorines: Universidad Nacional de General Sarmiento.

Ferraudi Curto, M. C. (2014). Ni punteros ni piqueteros. Urbanización y política en una villa del conurbano. Buenos Aires: Gorla.

Fernández Álvarez, M. I. (2016). (comp.). Hacer juntos (as). Dinámicas, contornos y relieves de la política colectiva. Buenos Aires: Editorial Biblos.

Frederic, S. (2009). Un barrio diferentes grupos: Acerca de dinámicas políticas en el distrito de La Matanza. En: A. Grimson, M. C. Ferraudi Curto y R. Segura (Comps.), La vida política en los barrios populares de Buenos Aires (pp. 249-267). Buenos Aires: Prometeo. 
Agustina Girado Análisis etnográfico del proceso de construcción de un accionar colectivo por el derecho a la vivienda y a la ciudad

Frederic, S. y Masson, L. (2006). Hacer política en la Provincia de Buenos Aires: cualidades sociales, políticas públicas y profesión política en los '90. Anuario de Estudios en Antropología Social, pp. 129-139.

Girado, A. (2018). Producir y gestionar la problemática habitacional de una ciudad media bonaerense. Un estudio antropológico de la agrupación "Mujeres Sin Techo". Tesis Doctoral. Facultad de Filosofía y Letras, Universidad de Buenos Aires.

Gravano, A., Silva, A. y Boggi, S. (2015). Ciudades vividas. Sistemas e imaginarios de ciudades medias bonaerenses. Buenos Aires: Editorial Café de las ciudades.

Gravano, A. (Comp.). (2005). Imaginarios sociales de la ciudad media. Emblemas, fragmentaciones y otredades urbanas. Estudios de Antropología Urbana. Tandil: Centro Editor de la UNICEN.

Gusfield, J. (2014). La cultura de los problemas públicos. El mito del conductor alcoholizado versus la sociedad inocente. México: Siglo XXI.

Lacarrieu, M. et.al. (2011). Procesos de recualificación y relegación en la ciudad de Buenos Aires Repensando la noción de ciudad-fragmento y la despolitización de lo urbano. Nueva Época, Año 24, no 66, 1-21. Recuperado de: http://www.scielo.org.mx/scielo.php?script=sci arttext\&pid=S0187-57952011000200002

Lazar, S. (2013). El Alto Ciudad, Rebelde. La Paz: Plural Editores Selección.

Manzano, V. y Moreno, L. (2011). Censar, demandar y acordar: demandas colectivas y políticas estatales en el gran buenos aires. Revista Pilquen, Sección Ciencias Sociales, Año XIII, № 14, 1-11. Recuperado de: http://revele.uncoma.edu.ar/htdoc/revele/index.php/Sociales/article/view/1597/1640

Manzano, V. (2013ㄹ). La política en movimiento. Movilizaciones colectivas y políticas estatales en la vida del Gran Buenos Aires. Rosario: Prohistoria Ediciones.

Manzano, V. (2013b). La política del tiempo: Palabra y cuerpo como experiencias de temporalidad en las luchas por la vivienda en la Ciudad de Buenos Aires. Ponencia presentada en la X Reunión de Antropología del Mercosur, Córdoba, Argentina.

Migueltorena, A. (2014). Políticas habitacionales y planeamiento del espacio urbano en Tandil, en el período actual. Huellas, $\mathrm{N}^{\circ}$ 18, 17-36. Recuperado de: https://cerac.unlpam.edu.ar/index.php/huellas/article/view/977

Perelmiter, L. (2011). Saber asistir: técnica, política y sentimientos en la asistencia estatal. Argentina (2003-2008). En: Vommaro, G. y Morresi, S. (Comps.), Saber lo que se hace. Expertos y política en la Argentina reciente (pp.135-173). Buenos Aires: Prometeo.

Quirós, J. (2011). El porqué de los que van. Peronistas y piqueteros en el Gran Buenos Aires (una antropología de la política vívida). Bueno Aires: Antropofagia. 
Rosa, M. (2011). Mas Eu Fui Uma Estrela de Futebol! As incoerências sociológicas e as controvérsias sociais de um militante sem-terra sul-africano. Mana, Estudos de Antropologia Social, Vol. 17, № 2. 365-394. Recuperado de: http://www.scielo.br/scielo.php?script=sci arttext\&pid=S0104-93132011000200005

Silva, A. y Gravano, A. (2013). Re-inventando espacialidades: gobierno electrónico e imaginarios urbanos en ciudades de rango medio. Ponencia presentada en la $X$ Reunión de Antropología del Mercosur, Córdoba.

Thomasz, A. G. (2013). Derecho a la vivienda y derecho a la belleza en la ciudad de Buenos Aires. En: Segregación y diferencia en la ciudad. Construyendo el derecho a la ciudad (pp. 61-81). Quito: FLACSO-Sede Ecuador. 